Woude (vande) Adriaan, 256. Wullems Françoise, 252.

- Brigitte, 256.

- Jan Baptist, 255.

Woumen (van) Johannes, 253 Wynckelman Frans, 255.

- Lodewijk, 253, 255, 257.

- Marie, 256.

- Theresia, 257.

- Marie, 255.

Wyse (de) Hendrik, 229.

Wulf (de) Herman, 227.

- Maarten, 243.

Zittere (de) Frans, 253.

\title{
SCOLASTRI EN RECTORES SCOLARUM AAN DE O. L. VROUW-KAPITTELSCHOOL TE BRUGGE (ca. 1480-1553)
}

Aanleiding tot deze bijdrage (1) waren de gegevens die wij aantroffen in de briefwisseling uit de studentenperiode van Peter Vulcanius (2) met betrekking tot het onderwijs aan de O. L. Vrouw-kapittelschool te Brugge. Het betrof een merkwaardig initiatief van de kanunnik Jacob van Halewijn (3) die, tegen het studieprogramma der kapittelscholen in (4), in 1529 grondige Griekse les-

(1) Voor onderstaande lijst maakten we gebruik van de volumina kapittelakten (afk. K.A.), met betrekking op de jaren 14801713. De eerste codex bevat de notulen 31 juli 1480-16 sept. 1501. De jaren sept. 1501-juli 1506 ontbreken in de ons bekende verzameling. Een tweede codex behandelt de jaren 19 juli 1506-7 juni 1529. Gezien in deze bundel een dubbele foliotatie werd gebruikt, onderscheidden we K.A. 19 juli 1506-4 aug. 1510; en K.A. 19 aug. 1510-7 juni 1529. Daarop volgt een codex 2 juni 1529-10 dec. 1554; en tenslotte K.A. 16 jan. 1547-20 dec. 1713; van deze laatste bundel zagen we de teksten na tot 1600 .

(2) A. Dewitte, Erasmus en Brugge, 1515-1536, HandEmuBr. XCIV (1957), blz. 5-15.

(3) Jacob van Halewijn, Heer van Maldegem, Uitkerke, Lembeke... was sinds 1524 kanunnik van de O.L. Vrouw-kerk. In 15351536 en 1538-1539 studeerde hij opnieuw te Leuven waar hij vroeger reeds de titel van Magister Artium had behaald: H. De Vocht, History of the foundation and the rise of the Collegium Trilingue Lovaniense, 1517-1550, 4 dln, Leuven 1951-1955, dl. II blz. 416; K.A. 1529-1554, fol. 64, 105 .

(4) In de steden waar geen scholen van de Broeders van het Gemene Leven bestonden - zoals te Brugge - waren de studenten verplicht, na hun opleiding aan de Kapittelschool, twee jaar de studie der Artes te volgen b.vb. aan één van de pedagogieën te Leuven, om speciaal het Grieks en de Filosofie (bonae of sacrae 
sen wilde laten geven en hiervoor Jan van Strazeele, die in 1534 P. Danès zou opvolgen als leraar in het Grieks aan het Collège de France, had aangeworven (5). Bij het behoud van dit initiatief werd Van Halewijn overigens ten zeerste bijgestaan door Daniël Spetebroot (6).

De kapittelakten, die wij ter verduidelijking hiervan consulteerden, vertonen echter geen sporen van deze opzet. Wij weten derhalve niet of na het heengaan van Van Strazeele deze lessen werden verder gezet. De correspondentie van Van Strazeele met P. Vulcanius is ook op andere punten belangrijk. We leren er uit b.vb. dat iemand als Honoratus Joannius (7), leerling van J.L. Vives, zich interesseerde aan het peil van het Brugse onderwijs (8), dat Spetebroot in zijn functie van rector scolarum - die functie lichten wij verder toe - zelf contact nam met mogelijke kandidaten (9), dat er contact bestond met de leraren der andere Brugse kapittel-

litterae) bij te werken. $\mathrm{Na}$ deze twee jaar kregen zij de titel van Magister Artium waarna zij hun studies aan de universiteit konden beginnen. De stichting Cuba van Jan de Witte te Brugge b.vb. had tot doel deze Artes te vervangen. Vanaf 1541 werd dus te Brugge doorlopend Grieks gedoceerd.

(5) Over Van Strazeele en Danès zie H. De Vocht, a.w., dl. II, blz. 415-416. Van Strazeele doceerde te Brugge o.m. Plato, Lucianus, Aristofanes, Theocritus en Homeros: Universiteitsbibliotheek Leiden (UBL), Cod. Vulc. 105 II, Van Strazeele aan P. Vulcanius, 23 maart (1529).

(6) De verwijzingen voor Spetebroot ( $†$ Brugge 16 mei 1553), zoon van Jan, geven wij verder in onze bijdrage. Spetebroot bleek in 1529-1530 zeer actief te zijn om een opvolger te vinden voor Van Strazeele, die klaarblijkelijk, als contubernalis van Van Halewijn (H. De Vocht, a.w., dl. II, blz. 415) slechts voorlopig aangeworven was. De kandidaten waren P. Vulcanius, die hier niet op inging, en Fl. de Griboal, zoon van Peter (raads- en kamerheer van Keizer Karel, mecenas voor Erasmus), die hoofdman was van het Brugse Vrije 1530-1534, en burgemeester in 1529, 1535. 1543, 1552. Hij studeerde te Leuven, Orléans, Bourges en Padua en werd in 1543 lid van de Grote Raad : H. De Vocht, a.w., dl. II blz. 155 .

(7) H. De Vocht, a.w., dl. II, blz. 401-407.

(8) UB L. Cod. Vulc. 105 II, Van Strazeele aan P. Vulcanius, 9 februari 1529, 23 maart (1529).

(9) Id., 9 februari 1529 : het betrof de leraren van de St.-Salvator-kapittelschool C. Lupus en Graefscepe. 
scholen (10) e.d.m. Blijkt de kapittelschool van O. L. Vrouw onder impuls van Jacob van Halewijn voor wat het Grieks betreft baanbrekend werk te hebben verricht, dan zijn de leraren waarvan wij de lijst publiceren, weinig bekend, terwijl ook de kanunniken niet deze studies deden als wij b.vb. aantreffen bij de kanunniken van St.-Donaas. Een vergelijkende tabel voor de jaren 1529-1549 toont ons b.vb. dat voor St.-Donaas 10 namen te vinden zijn van studenten die hun studies verder zetten aan de universiteiten van Leuven, Parijs, Keulen, Mainz, en Rome (11); voor de O. L. Vrouw-kerk kennen wij maar twee namen van studenten, die te Leuven verbleven (12). Anderzijds zijn twee kanunniken van O. L. Vrouw zeer bekend geworden : H. Busleyden, de stichter van het Collegium Trilingue te Leuven (13), en P. Cotrel die te Doornik het Collegium Bilingue oprichtte (14). $\mathrm{Zij}$ waren echter door hun functie niet tot resideren gedwongen, zodat ze zonder invloed bleven, althans wat het onderricht betreft.

Wat nu de scolae betreft waar de rectores, leraren aan de kapittelschool, waren aangesteld: G. Cassander resumeerde in 1541 te Brugge zelf het programma ervan als de studie der Grammatica (15). Daaraan ontbrak volle-

(10) Id., 9 februari, 23 maart, 23 april 1529; buiten de leraren hierboven vermeld: Gerard Bachusius uit Maaseik in 1523 rector scolarum, in 1537 kanunnik van St.-Donaas : A. Dewitte, Erasmus en Brugge, blz .16.

(11) C. Weerde (1529-1536), C. Wouters (1533; 1542-1554), E. Heems (1533-1552), Fr. Van Gael (1540-1541), Heetvelde (15401541), J. Ressert (1542-1552), A. Barradot (1544-1549), P. Damant (1544-1561), J.R. de Weerdt (1545-1558), J.B. de Langhe (1549-1557) : A. Himpe, Het Humanisme aan het St.-Donaaskapittel te Brugge, diss., Gent 1941, blz. 132-139. $38 \mathrm{v}$

(12) K. Michault en J. Van Halewijn : K.A. 1529-1554, fol. 6,

(13) Het enige spoor van contact met Brugge vinden wij in het feit dat zijn poëzie bij zijn overlijden in het bezit was van Jan Fevyn: F. Nève, Le Conseiller Jérome Busleyden (Bull. Acad. Roy. Belg., Classe Lettres, 2e reeks, nr. 36, 1873) blz. 377-431.

(14) P. Cotrel (geb. 1461) kreeg in 1534 de 11e prebende aan de O. L. Vrouw-kerk. Hij was tevens deken van het Kapittel van Doornik en werd aartsdiaken van Gent: K.A. 1529-1554, fol. 50, 54; H. De Vocht, a.w., dl. I, blz. 525.

(15) G. Cassander, Oratio in laudem urbis Brugensis (uitg. C. Carton, Gent 1847) blz. 23-24. Volgende handboeken werden zeker gebruikt in de Brugse kapittelscholen: Introductorium Juvenum 
dig, zegde Cassander, de kennis van de Dialectica en de Retorica, naast een voldoende kennis van het Grieks om met goed gevolg de universiteit te beginnen.

Studenten waren, naast de zonen der gegoede standen (handelaars, hovelingen, stadsfunctionarissen) uit de omgeving : familiares der kanunniken, die recht hadden op gratis onderwijs, en chorales en refectionales, armenkinderen speciaal omwille van hun mooie stem aangeworven (16).

Wat nu de gegevens uit de kapittelakten betreft : uit onderstaande lijst blijkt duidelijk dat de meeste rectores scolarum, leraren onder het toezicht van de scholaster, de titel van Magister Artium bezaten. De scholaster of schooldirecteur, die uiteindelijk door de overige kanunniken beïnvloed werd, was steeds een kanunnik. Uit de hieronder aangehaalde voorbeelden van Paulus de Porta en Bernard de Curia kan worden verondersteld dat de scholaster zich een plaatsvervanger kon kiezen zonder hierom zelf zijn functie te verliezen. Het was echter de uitdrukkelijke taak van de scholaster de nieuwe rectores aan het kapittel voor te stellen (17), en ze daarna naar de school te begeleiden om hen de sleutels, teken van hun nieuwe ambt, over te reiken (18). De eed, die de rectores bij hun aanvaarding door het kapittel dienden af te leggen, bleef ons bewaard in een kopie uit de jaren 1545-1548 (19). Ze dienden de privileges, statuten en consuetudines van kerk en school te eerbiedigen; er werd een bijzondere nadruk gelegd op hun verantwoor-

in Grammaticam (Antwerpen 1515) van de hand van Jan De Spouter, een werk dat verdedigd werd door de kanunnik van St.Donaas Jacob de Meyere; Ars Versificatoria, van de secretaris van St.-Donaas : St. Comes, een werk dat het voorgaande aanviel $(H$. De Vocht, a.w., dl. III, bl. 433); - en De Veteri et recta pronuntiatione Linguae Graecae Commentarius (Antwerpen 1565) van de Bruggeling A. van Meetkerke. In St.-Donaas werden bovendien omstreeks 1520 de Colloquia en Opus de Conscribendis Epistolis van Erasmus gebruikt: P.S. Allen en H. M. Allen, Opus Epistolarum Desiderii Erasmi Roterodami, denuo recognitum et auctum, 11 dln., Oxford 1906-1947, dl. IV, brief 1286.

(16) A. C. De Schrevel, Histoire du Séminaire de Bruges, dl. I, Brugge 1895, blz. 30-36.

(17) Juist hetzelfde was gebruikelijk in de St--Donaas-kapittelschool : A. C. De Schrevel, a.w., blz. 143.

(18) K.A. 1529-1554 fol. 25 v.

(19) $K \cdot A \cdot 1529-1554$, schutblad. 
delijkheid ten overstaan van de executio et promotio cultus et officii divini. We zien dat rectores herhaaldelijk om hun tekortkomingen tegen die passus worden afgesteld. Ten slotte is het hen verboden ullas exactiones vel novitates in eisdem scolis facere. Dit gaat wellicht nog terug op de reactie tegen het humanisme omstreeks 1520 (20). Hebben de rectores die eed gezworen en ondertekend, dan krijgen ze een koorzetel toegewezen cum lucro et emolumentis. De school zelf genoot het monopolie van onderwijs binnen het gebied waarover het kapittel bevoegd was. De voorbeelden van A. Nepos (1522), F. Schilt (1539) en J. Hacke (1553) tonen aan dat hiertegen door de gewezen rectores zelf werd gezondigd (21). Het geval J. Hacke is bovendien een aanwijzing dat scolares en chorales toen reeds bij de rector inwoonden (22). Tot slot is het belangrijk erop te wijzen dat het groot aantal benoemingen tussen de jaren 15311553 kan afhankelijk zijn van een verscherpte controle op het onderwijs zelf.

\section{Scolastri}

De vroegst opgetekende scholaster is Peter Paton, clericus. Doch uit een fundatie uit de voorgaande tijd bleef ons de naam bewaard van de scholaster Diericx, die nu eens Theoderic, dan weer Martinus als voornaam krijgt toegewezen (23). Hij trad in deze functie vóór 1480 op.

Van Peter Paton kunnen we vermoeden dat hij reeds vanaf 1482 als scholaster optrad (24). Bij zijn dood werd hij op 21 dec. 1492 opgevolgd door Mag. Paulus de Porta, toen deken aan de St.-Hermeskerk te Ronse (25). Op 4 aug. 1494 verzaakte deze echter aan zijn functie, daar hij te Leuven zijn studies voortzette (26).

(20) A. Dewitte, a.w., blzn. 11, 13.

(21) Juist hetzelfde deed zich voor t.o.v. de St.-Donaas-kapittelschool : A. C. De Schrevel, a.w., blz. 59.

(22) Dit was sinds 1550 het geval met de rector van de St.-Donaaskapittelschool : A. C. De Schrevel, a.w., blz. 59.

(23) K.A. 1510-1529, fol. 41 v., 59; K.A. 1529-1549, fol. 259.

(24) K.A. 1480-1501, fol. 3 .

(25) K.A. 1480-1501, fol. 57, nr. 382. Een Hermes de Porta, uit Ronse, werd op 27 febr. 1477 aan de Leuvense Universiteit ingeschreven: J. Wils, Matricule de l'Université de Louvain, II, 31 aug. 1453-31 aug. 1485, Brussel 1946, blz. 358.

(26) K.A. 1480-1501, fol. 61. 
Vanaf jan. 1499 trad hij weerom als scholaster op, na een beslissing van het kapittel, die hem uit Leuven terugriep (27). Of hij tussen de jaren 1494-1499 een plaatsvervanger kreeg, blijkt niet uit de kapittelakten. Evenmin kunnen we precies vaststellen wanneer hij (zijn ambt neerlegde, daar over de jaren 1501-1506 de notulen ontbreken.

Op datum 29 mei 1514 dan vernemen we dat de toenmalige scholaster, Bernard de Curia - hij had als plaatsvervanger Henricus de Zueene (28) aangenomen - tot het rectoraat te St.-Niklaas was benoemd, en zo de functie vrij gaf (29). Bernard de Curia ontmoetten we reeds voorheen in de K.A., toen hij als notarius publicus en commissarius van het Hof van Doornik aanwezig was, en de notulen maakte bij de verkiezing van Franciscus de Melun tot proost van de O.L. Vrouwkerk, 1506 (30).

Op 29 mei 1514 werd Mag. Georgius Tayspil als opvolger aangeduid (31). Deze liet zich vervangen door Michael Brunyau, doch slaagde erin reeds op 9 dec. 1515 zijn broer Mag. Johannes Tayspil tot scholaster te laten benoemen (32).

Johannes Tayspil bleef dit ambt uitoefenen tot 17 juni 1532 (33), datum waarop Mag. Daniel Spetebroot zijn taak overnam. Bij de dood van D. Spetebroot werd Jacob They met deze functie belast, 20 juni 1553 (34).

De laatste scholaster waarover melding in de K.A., is Gulielmus Valerius, die ca. 1566-1567 als dusdanig in de notulen verschijnt (35).

(27) Id., fol., 61, 85 v., 91 v.

(28) Een Henricus Zuene werd op 19 febr. 1483 te Leuven opgetekend : J. Wils, a.w. blz. 469.

(29) $K \cdot A$. 1510-1529, fol. 44. De functie was blijkbaar reeds vacant sinds februari 1514 : $I d$. fol. $41 \mathrm{v}$.

(30) K.A. 1506-1510, fol. 3-13 v.

(31) K.A. 1510-1529, fol. 44. Een broer van G. Tayspil, Daniël, werd suffragaan van de bisschop van Terwaan en in 1524 abt van Vormezele waar hij in 1533 overleed. Een andere broer, Jan Tayspil was kanunnik van de St.-Donaaskerk: H. De Vocht, a.w., dl. II, blz. 77 .

(32) K.A. 1510-1529, fol. 63 v.-64.

(33) K.A. 1529-1554, fol. 38 v.

(34) Id., fol. 239-240.

(35) $K \cdot A .1547-1713$, fol. 96,97 v., $98,99$. 


\section{Rectores Scolarum}

De vroegste benoemingsdatum tot het rectoraat is 20 aug. 1499. Vóór die tijd bezitten we echter een drietal namen van rectores, zonder echter een preciese datum voor het aanvaarden van hun functie te kunnen vooropzetten.

Zo treffen we in 1482 de rector Theobald Vlamings aan, in een geding voor het kapittel, o.m. om zijn absenteïsme in de koordiensten en om de verwaarlozing van zijn rectorale functie (36).

In 1487 komt Hubert Appels als rector in de notulen voor, met de titel van Magister Artium. In sept. 1507 wordt hij als vicarius perpetuus vermeld, een waardigheid die hij op 19 juli 1513 neerlegde (37).

Als opvolger van Appels is Willem Zuerinck, Mag. Art., (38) o.m. in 1498 opgetekend. Op 22 juni 1499 diende de scholaster Paulus de Porta klacht in tegen hem, daar hij was "totus vagans, negligens, et dissolutus, nichil curans de informacione juvenum". Hij werd daarom reeds op 20 aug. vervangen door Johannes Neerinc (39).

Deze vinden we reeds in 1491 als presbyter vermeld, heeft bij zijn benoeming tot rector de titel van Mag. Art., en vervulde in 1500 de functie van notarius. Op 22 aug. 1500 trad hij nog als rector op (40). De juiste vervaldatum van zijn rectoraat is ons niet bekend. Wellicht viel die tussen de jaren 1501-1506, waarvan de notulen ons niet bekend zijn.

Pas in febr. 1512 duikt de naam van een nieuwe rector op; het betreft Arnold Nepos (De Neve), die reeds sinds 1510 de functie van secretaris van het kapittel waarnam. In 1515 werd hij capellanus de gremio en hij bleef secretaris tot 1523 . Hij werd waarschijnlijk

(36) K.A. 1480-1501, fol. 3. Een Vlamings was in 1467 secretaris van het kapittel van St.-Donaas: A.C. De Schrevel, a.w., blz. 119. De Matricula van de Leuvense Universiteit vermeldt de Bruggeling Nych. Vlaminc als student op 29 aug. 1477: Jos. Wils, a.w. blz. 363.

(37) $K \cdot A \cdot 1480-1501$, fol. 33 v.; $K \cdot A \cdot 1506-1510$, fol. $27,36$.

(38) Een Franco Zuerinck, Torn. dioc., werd te Leuven ingeschreven op 29 juli 1464: Jos. Wils, a.w. blz. 134.

(39) K.A. 1480-1501, fol. 31, 64 v., 81, 83 v., 94, 98, 101.

(40) K.A. 1480-1501, fol. 54 v., nr. 281, fol. 101, 115, 124. 
vóór 1515 in zijn rectoraat vervangen door Filip Coorne (41).

Coorne zelf trad reeds af op 29 okt. 1517. Op die datum werd Daniel Spetebroot, presbyter, als rector aangeduid (42). Naar de benoemingsakte van zijn opvolger, Peter van den Donck, de dato $31 \mathrm{dec}$. 1517, te oordelen, nam Spetebroot die taak niet op (43).

Op 31 aug. 1520 werd Peter van den Donck op zijn beurt vervangen door Jacob Balde, Mag. Art. (44).

Op 22 febr. 1522 volgde toen de herbenoeming van de hoger geciteerde Daniël Spetebroot, nu Mag. Art. genoemd. Daaraan ging een geding vooraf, ingespannen door de scholaster J. Tayspil tegen A. Nepos, omdat deze o.m. commensales en scolares in zijn huis les gaf, te nadele van de kapittelschool (45).

In Daniël Spetebroot, die tot 1531 rector bleef, en vanaf 1532 scholaster werd van de O. L. Vrouw-kapittelschool, vond de school waarschijnlijk de enige persoon die zowat dertig jaar zijn krachten aan de ontwikkeling en de uitbouw van het onderwijs kon besteden. Dit komt duidelijk naar voor in de hierna volgende lijst rectores waarop tussen 1531-1553 niet minder dan twaal titularissen voorkomen.

Op 8 febr. 1531 werd Adriaan van de Velde, Mag. Art., als opvolger van Spetebroot aangeduid (46). Reeds op 26 sept. van het volgend jaar liet hij zijn rectoraat over in de handen van Mag. Art. Franciscus Schilt (47). In april 1539 werd deze aangemaand een groter stiptheid aan de dag te leggen; de 6e aug. daaropvolgend kreeg hij zijn ontslag daar hij verdacht werd van " $a c$ cessus et conversatio in domo cujusdam juvenculae",

(41) $K \cdot A \cdot 1506-1529$, fol. 19 v., 1-191, 56 v.

(42) K.A., 1506-1529, fol. 87 v.

(43) Id., fol. 94 v. In de K.A. 1506-1529, fol. 167, komen de namen voor van de prebendarii Georgius en Vincentius van der Donck.

(44) $K \cdot A ., 1506-1529$, fol. 94 v., 162 v.

(45) Id., fol. 177 v., 178.

(46) $K . A ., 1529-1554$, fol. 25 v.; Daniël Spetebroot zegde volgens Van Strazeele over hem: non admodum aptus est huic rei : UBL, Cod. Vulc. 105 II, Van Strazeele aan P. Vulcanius, 9 februari 1529. Dit is misschien de reden waarom zijn rectoraat zo kort was.

(47) Id., fol. 41 v. 
verder omdat hij naliet Mis te lezen, en bij dag en nacht op suspecte plaatsen in burgerkostuum was gezien (48). In zijn plaats werd dan Mag. Jacob Woestland, vicarius diaconalis, aangeduid voor het rectoraat.

F. Schilt legde zich niet onvoorwaardelijk hierbij neer, want op 3 sept. 1539 werd hem verder verbod opgelegd nog commensales en scolares in zijn huis les te geven (49).

Op 21 juli 1540 bood J. Woestland reeds zijn ontslag aan; Mag. Jacob van Gelder zou de taak overnemen (50). Van Gelder echter gaf op 29 okt. van hetzelfde jaar zijn rectoraat reeds door (51) aan Adriaan van der Lovene (52).

Hierna kwamen, in vlugge opvolging, de benoemingen van Mag. Jacob Weghescheede (53), 7 juni 1542; Mag. Filip van den Eecke (54), febr. 1543; Mag. Antoon Coquellen (55), 4 okt. 1546; Petrus Borree (56), 18 okt. 1547; Vincent Huucen (57), 10 dec. 1550; en Joannes Hacke (58), 19 jan. 1551.

Op 28 juli 1553 werd J. Hacke tot rector benoemd van de St.-Salvatorschool (59). Zonder het kapittel van O.L. Vrouw te verwittigen, verliet Hacke zijn post en slaagde erin een deel der scolares en chorales met zich mee te nemen (60). Het O. L. Vrouwkapittel stelde in der haast de oud-rector P. Borree in zijn plaats, 2 aug. 1553, en benoemde ten slotte de volgende

(48) Id., fol. 99, 106, 106 v.

(49) K.A. 1529-1554, fol. 109.

(50) Id., fol. 115.

(51) Id., fol. 120.

(52) Op 12 jan. 1541 moest hij voor het kapittel verschijnen voor smaad en verwondingen aan J. Woestland toegebracht: Id., fol. 123 v. Tussen de jaren 1535-1538 wordt hij als leraar aan de Bogaerdenschool vermeld: L. Gilliodts-Van Severen, Inventaire diplomatique de l'ancienne école Bogaerde à Bruges... dl. III, Brugge 1900, blz. 1000, 1094.

(53) Id., fol. 132. In 1545-1546 was hij regent aan de Bogaerdenschool : L. Gilliodts-Van Severen, a.w., blz. 1094.

(54) Id., fol. $179 \mathrm{v}$

(55) Id., fol. $189 \mathrm{v}$.

(56) Id., fol. 203.

(57) Id., fol. 232.

(58) Id., fol. $232 \mathrm{v}$.

(59) K.A. St.-Salvator, 1539-1558, fol. 169-169 v.

(60) K.A. O.L. Vrouw, 1529-1554, fol. 246 v. 
dag Mag. Roland van den Bussche, uit Roeselare, tot nieuwe rector (61).

In de K.A. tot 1600 vinden we nog, in mei 1563, Antoon Wante geciteerd als ludimagister (62). Gezien ook J. Hacke in 1553 ludimagister werd genoemd, waar rector werd bedoeld (63), was Wante wellicht een opvolger van Van den Bussche in het rectoraat.

A. DEWITTE

\section{DE WOONPLAATSEN VAN J. L. VIVES EN ZIJN ECHTGENOTE TE BRUGGE}

Wanneer Jan Lodewijk Vives, de beroemde Spaanse humanist en filosoof, zich omstreeks 1521 te Brugge vestigde, nam hij zijn intrek in een huis, dat toebehoorde aan een rijke Spaanse koopman, Petrus de Aguirra. Dit huis stond in de Korte Vlamingstraat, het gedeelte van de Vlamingstraat tussen het Beursplein en de Vlamingbrug.

Naderhand verhuisde Vives naar de Lange Winkel, de huidige Spanjaardstraat. Intussen was zijn weldoener, Petrus de Aguirra, op 20 april 1522 gestorven. Wellicht is hij in het huis van de Lange Winkel verder tot zijn afsterven blijven wonen en is het aldaar dat hij de heilige Ignatius van Loyola, bij een van zijn bezoeken aan Brugge, ter tafel heeft uitgenodigd (1).

Vives overleed op 6 mei 1540 en werd in de SintDonaaskerk te Brugge begraven. De dag van zijn uitvaart werden ook de klokken van de Sint-Gilliskerk geluid, waarschijnlijk omdat hij op de Sint-Gillisparochie woonde. De Korte Vlamingstraat en de Spanjaard-

(61) Id., fol. 247 .

(62) $K \cdot A \cdot 1547-1713$, fol. 76 .

(63) K.A. O.L. Vrouw, 1529-1554, fol. $246 \mathrm{v}$.

(1) Zie : A. VIAENE, Ignatius van Loyola te Brugge, 1528-1530, in Handelingen van het Genootschap voor Geschiedenis "Saciété d'Emulation" te Brugge, dl. XCIII (1956), blz. 145-155. 